\title{
RETINOPATHY OF PREMATURITY: A PROSPECTIVE STUDY. REVIEW AT SIX MONTHS
}

\author{
D. LAWS ${ }^{1}$, D. E. SHAW ${ }^{2,3}$, J. ROBINSON ${ }^{2,3}$, H. S. JONES 3 , Y. K. NG ${ }^{2}$, A. R. FIELDER ${ }^{2,3}$ \\ Birmingham and Leicester
}

\begin{abstract}
SUMMARY
A cohort of infants of birthweight $\leqslant 1700 \mathrm{~g}$ studied prospectively for retinopathy of prematurity (ROP) has been reviewed at 6 months corrected age and the findings related to the neonatal data. The overall incidence of strabismus was $6.4 \%(30 / 468)$, rising from $3.1 \%(7 / 229)$ without ROP to $29.2 \%(7 / 24)$ with stage 3 . Strabismus and fusional ability were significantly related to presence and severity of ROP, and abnormal neonatal cranial ultrasound findings. Binocular visual acuity was measured in 340 infants between 20 and 40 weeks corrected age. Eight were subnormal, all due to neurological problems. For the remainder, despite falling within the normal range, there was a significant trend $(\boldsymbol{p}<\mathbf{0 . 0 0 1 )}$ for lower acuities with increasing ROP severity. Cycloplegic refraction on 387 infants revealed, with increasing ROP severity: 1, a significant trend towards myopia; 2 , increased magnitude of astigmatism; 3 , alteration of the astigmatic axis; 4 , increased incidence of anisometropia. For the first three categories there was an insignificant trend between no ROP and stage 2, reaching significance only between stage 2 and 3. The predominant axis of astigmatism in infants without $\mathrm{ROP}$ was between $60^{\circ}$ and $120^{\circ}$, but with ROP there was a significant trend away from this direction.
\end{abstract}

Infants born preterm are at risk of experiencing a variety of ophthalmic problems during the neonatal period, sometimes with sequelae which may become apparent later in infancy, childhood or adult life. The best-known example of the first is retinopathy of prematurity (ROP) and the later associations or complications of preterm birth include visual acuity deficits, ocular motility disorders, optic atrophy and refractive errors. ${ }^{1-9}$ In order to investigate the causation of the ophthalmic sequelae of prematurity, information on the perinatal period is mandatory, and ideally should include details of both systemic and oph-

\footnotetext{
'Birmingham and Midland Eye Hospital, Birmingham, UK.

${ }^{2}$ University of Leicester Medical School, Leicester, UK.

${ }^{3}$ University of Birmingham Medical School, Birmingham, UK.

Correspondence to: A. R. Fielder, MRCP, FRCS, FCOphth, Birmingham and Midland Eye Hospital, Church Street, Birmingham B3
} 2NS, UK. thalmic events. There have, however, been relatively few studies on the ophthalmic outcome of low birthweight infants which consider in detail neonatal data. ${ }^{10-19}$

Recently we undertook a prospective study of ROP in the East Midlands of England which was specifically designed to investigate its natural history. ${ }^{20}$ Here we present the ophthalmic findings of this cohort obtained at 6 months corrected age and compare them with the findings obtained during the neonatal period.

\section{PATIENTS AND METHODS}

A prospective study to determine the incidence and severity of ROP in a geographically defined population was undertaken over a 23-month period between 1 July 1985 and 31 May 1987 in the East Midlands of England. ${ }^{20}$ All infants with a birthweight $\leqslant 1700 \mathrm{~g}$ who survived 3 weeks were enrolled from five neonatal units in the cities of Derby, Nottingham and Leicester. No infant received supplemental vitamin $\mathrm{E}$. The epidemiological aspects of this cohort have been reported. ${ }^{21}$

Commencing at 3 weeks of age, ophthalmic examinations were performed weekly during the infant's stay on the neonatal unit until 12 weeks of age. After discharge, infants were examined every 2 weeks until 12 weeks of age, and thereafter as clinically indicated, with a final assessment at 6 months corrected age. All ophthalmic examinations at this time were performed by one ophthalmologist (ARF). Before 12 weeks, examinations were performed following instillation of topical anaesthesia (oxybuprocaine hydrochloride $0.4 \%$ ) using an eyelid speculum and scleral indentation to visualise the entire $360^{\circ}$ of the retinal circumference. Indirect ophthalmoscopy was performed using a $28 \mathrm{D}$ lens preceded by dilatation of the pupils with cyclopentolate $0.5 \%$ drops \pm phenylephrine $2.5 \%$. Results were recorded on a computer coding form with the acute changes of ROP documented according to the International Committee for Classification of Retinopathy of Prematurity. ${ }^{22}$ Cicatricial ROP was recorded using the classification of Reese and associates. $^{23}$

The ophthalmic examination at around 6 months cor-

Eye (1992) 6, 477-483 
rected age included visual acuity measurement, recorded using the acuity card procedure ${ }^{24}$ (byARF except for orthoptic assessment by DP for some infants in one centre). Binocular visions were measured; however, monocular acuities were also obtained in certain instances, such as those infants with ROP stage 3 or above. Assessment of ocular motility included examination for the presence of strabismus and nystagmus. Fusional ability was assessed using a $20 \mathrm{D}$ base-out prism in front of each eye. Retinoscopy was performed, with particular care being taken to remain on the optic axis, following cycloplegia induced by instillation of cyclopentolate $1 \%$ eyedrops. Results were recorded with positive cylinder notation. Where given, mean spherical equivalents were calculated from the formula: $: 25$

Spherical equivalent $=[ \pm$ sphere $]+0.5[ \pm$ cylinder $]$

Fundus examination at the 6 month visit was performed using a $20 \mathrm{D}$ lens for greater magnification and a $28 \mathrm{D}$ lens to examine the retinal periphery. Scleral indentation and an eyelid speculum were not used at this time. In addition the degree of tortuosity of the retinal arterioles near the optic disc was recorded on a 5-point scale from 0 to ++++. Any other ophthalmic abnormalities, not directly related to ROP, were also noted.

Data were stored on the mainframe computer (IBM 3090) at Birmingham University and analysed with the statistical package SPSS. Relationships between categorical variables were investigated with the chi-squared test (Tables I-III, VII, VIII). Visual acuities and refractive components between ROP groups were tested by analysis of covariance with ROP group as factor in the model, and age at testing as covariate. Various other factors that may confound the ROP group comparison were introduced as covariates in the model. In the case of overall significant group differences, pairwise comparisons between groups were conducted in order to identify the source of the significance.

Non-ophthalmic data were also recorded. These included details of pregnancy, labour, resuscitation, postnatal illness and cranial ultrasound (performed in four out of five neonatal units). Ultrasound abnormalities considered significant were:

1. Cystic periventricular leucomalacia or persistent flare.

2. Ventricular dilatation persistent for more than 1 week.

3. Periventricular haemorrhage excluding subependymal haemorrhage.

4. Miscellaneous neurological abnormalities (e.g. primary neurodevelopmental disorders).

Table I. Cranial ultrasound findings and stage of acute ROP in 321 infants

\begin{tabular}{lrrrrr}
\hline & \multicolumn{5}{c}{ Stage of ROP } \\
\cline { 2 - 6 } Cranial & \multicolumn{1}{c}{0} & 1 & 2 & $3 / 4$ & Total \\
\hline ultrasound & \multicolumn{1}{c}{114} & 78 & 35 & 9 & 236 \\
Normal & 114 & 26 & 23 & 13 & 85 \\
Total & 137 & 104 & 58 & 22 & 321 \\
\hline
\end{tabular}

Permission for this study was obtained from the Ethical Committees of Leicestershire, Nottingham and Southern Derbyshire Health Authorities.

\section{RESULTS}

The cohort consisted of 572 infants who satisfied the birthweight criteria. The gestational age (GA) and birthweight (Bwt) distributions of the cohort have been described previously. ${ }^{20}$ Mean GA was 30.8 weeks (SD 3.0 weeks) and mean Bwt $1328 \mathrm{~g}$ (SD $270 \mathrm{~g}$ ). There were 319 males and 253 females ; 451 were singletons, 115 twins and 6 the survivors of multiple pregnancies. Ethnic origin was as follows: Caucasian, 465; Asian, 66; Afro-Caribbean, 24; others, 17. Neonatal cranial ultrasound scan data were available on 321 infants, and significant abnormal intracranial events (see earlier) were noted in $85(26.5 \%)$. Unfortunately not all tests (e.g. cranial ultrasound) were performed on all infants. To avoid confusion, therefore, it is important that the reader does not always refer to the entire cohort, but only to that proportion on whom that particular investigation was performed. Direct comparison between tests is thus not always possible.

The cohort was reduced to 524 by 3 months and ophthalmic examinations were performed on $481(91.8 \%)$ on or after this corrected age. Data were collected on 3958 ophthalmic examinations, 1213 performed after 12 weeks. Acute ROP developed in 291 infants out of the 572 $(50.9 \%)$. The maximum stage reached was 1 in 171 $(29.9 \%), 2$ in $93(16.3 \%), 3$ in $25(4.4 \%)$ and 4 in $2(0.3 \%)$. Cicatricial ROP developed in 10 eyes of $6(1.1 \%$ of 572$)$ infants (ranging from 880 to $1300 \mathrm{~g} \mathrm{Bwt}$, and from 25 to 28 weeks GA), with grade 1 in 6 eyes, II in 1 eye, and III in 3 eyes. The one infant who developed grade III cicatricial disease bilaterally, died before the 6-month assessment, and is not therefore included in the subsequent analysis. One eye required cryotherapy, and this eye subsequently developed cicatricial stage 3 ROP. There was a highly significant association between cranial ultrasound findings and both the presence $(p=0.001)$ and stage $(p<0.001)$ of ROP (Table I).

The results of examination for strabismus were available in 468 infants. Strabismus was present in 30 infants (6.4\%): 20 convergent and 10 divergent (Table II). The incidence of strabismus increased with both the presence and stage of acute ROP as follows: no ROP, 7/229 (3.1\%); stage 1, 10/144 (6.9\%); stage 2, 6/71 (8.5\%), and stage $3 / 4,7 / 24(29.2 \%)$. There was a significant relation between strabismus and both presence and stage of ROP $(p=0.007$ and $p=0.001$ respectively), and abnormal

Table II. Stage of acute ROP and the presence of strabismus at 6 months corrected age for 468 infants

\begin{tabular}{lcccc}
\hline Stage of ROP & Convergent & Divergent & None & Total \\
\hline 0 & 5 & 2 & 222 & 229 \\
1 & 7 & 3 & 134 & 144 \\
2 & 4 & 2 & 65 & 71 \\
$3 / 4$ & 4 & 3 & 17 & 24 \\
Total & 20 & 10 & 438 & 468 \\
\hline
\end{tabular}


Table III. Stage of acute ROP and fusional ability at 6 months corrected age for 454 infants

\begin{tabular}{lccc}
\hline Stage of ROP & Positive & Negative & Total \\
\hline 0 & 207 & 14 & 221 \\
1 & 127 & 14 & 141 \\
2 & 57 & 12 & 69 \\
$3 / 4$ & 14 & 9 & 23 \\
Total & 405 & 49 & 454 \\
\hline
\end{tabular}

cranial ultrasound events in the neonatal period $(p<0.001)$. Fusional ability was tested in 454 infants; it was abnormal in $49(10.8 \%)$, and was also significantly associated with both the presence and stage of ROP ( $p=0.005$ and $p<0.001$ respectively; Table III), and with abnormal cranial events $(p<0.001)$. It was not possible to differentiate the individual effects on strabismus and fusion of prematurity, abnormal cranial ultrasound and ROP.

Binocular visual acuity was recorded in 431 infants using the acuity card procedure, and the 340 tests (78.9\%) undertaken between 20 and 40 weeks corrected age have been analysed. Analysis of covariance demonstrated that visual acuity increased significantly with age $(p=0.003)$. In 8 infants, acuities fell below the normal range, and 2 of these had no grating detection. No infant with reduced acuity had bilateral retinal abnormalities considered sufficient to account for this finding, but all had severe neurological disorders. The 8 with reduced acuity (these represent all 431 tested) were removed before analysis, but the remainder, despite falling within the normal range, exhibited a significant trend $(p<0.001)$ for lower values with the presence and severity of ROP (Fig. 1). This was only significant when taken as a whole, and not between each stage. This effect persisted after correction for both $\mathrm{GA}$ and age at examination. Furthermore, correction for abnormal cranial ultrasound results $(n=183)$ did not significantly alter this trend, neither did exclusion of those

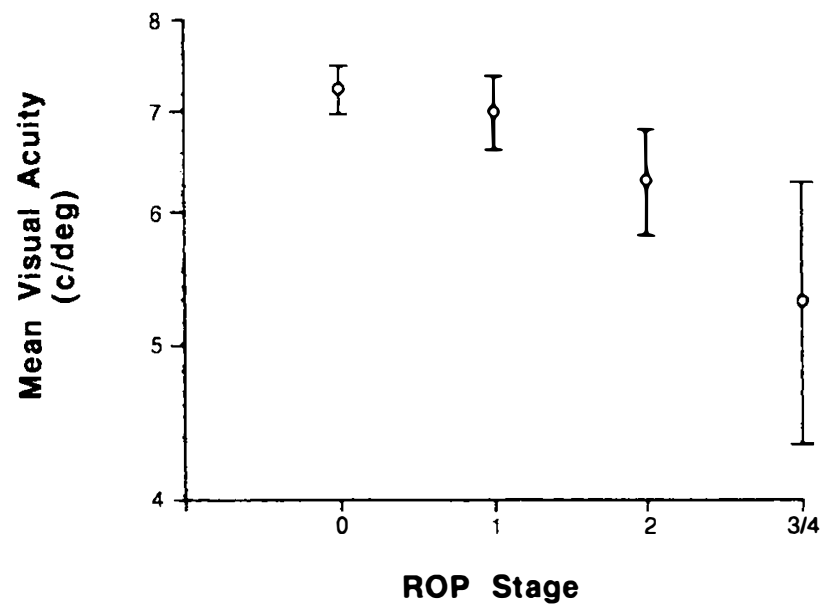

Fig. 1. Stage of acute ROP and mean visual acuity in cycles per degree in 340 infants tested between 20 and 40 weeks corrected age. There is a significant decrease with increasing ROP stage $(p<0.001)$. Acuities are given with $95 \%$ confidence intervals.

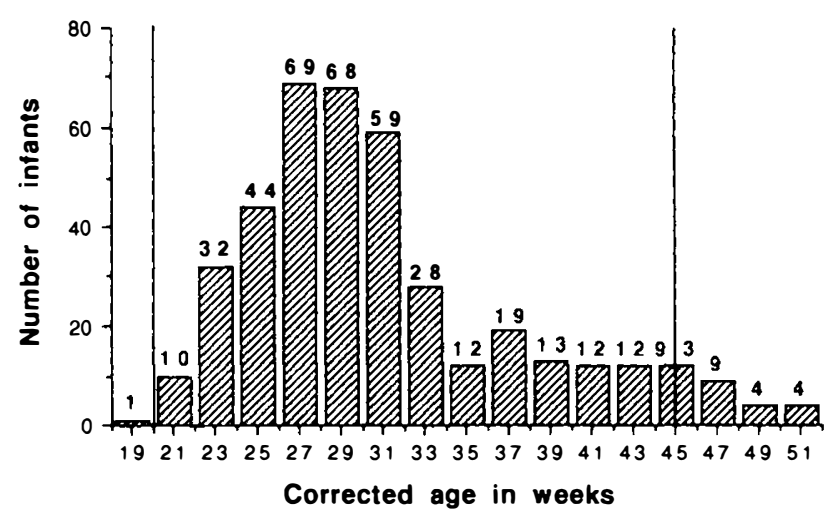

Fig. 2. Corrected age at refraction. Numbers on the tops of histogram bars denote numbers of infants examined at each age and vertical lines show inclusion criteria for refractive analysis.

infants with cicatricial disease (including dragged discs although, as mentioned, in no case were these bilateral). When acuity was plotted against Bwt and GA, no trend was observed. Abnormal cranial ultrasound was not associated with reduced acuity $(p=0.137)$. No infant was blind due to ROP.

Retinoscopy was performed on 469 infants and the 387 tests $(82.5 \%)$ undertaken between 20 and 45 weeks corrected age (Fig. 2) have been analysed. Using analysis of covariance and correcting for age at testing, there was a significant inverse association between stage of ROP and the magnitude of the mean plus spherical correction in each eye (i.e. a trend toward myopia, $p<0.001$ for right and left eyes, Table IV). Mean astigmatism was significantly increased with higher stages of ROP for both eyes (right, $p=0.010$; left, $p=0.009$; Table $\mathrm{V}$ ). There was a significant association between ROP stage and mean spherical equivalents for each eye (right, $p=0.002$; left, $p=0.003$; Table VI). However, the only single significant step for both spheres, spherical equivalent and astigmatism was between stages 2 and 3, although there was an insignificant trend from stages 0 to 2 . For infants without ROP the predominant axis of astigmatism was $60^{\circ}-120^{\circ}$, but with increasing severity the proportion of $60^{\circ}-120^{\circ}$ decreased and the proportion of $150^{\circ}-30^{\circ}$ and other axes

Table IV. Stage of acute ROP and mean spheres (in dioptres) for 387 infants refracted between 20 and 45 weeks corrected age

\begin{tabular}{lcc}
\hline Stage of ROP & $\begin{array}{c}\text { Right dioptres } \\
\text { (range) }\end{array}$ & $\begin{array}{c}\text { Left dioptres } \\
\text { (range) }\end{array}$ \\
\hline 0 & +1.45 & +1.47 \\
& $(-2.75$ to +7.50$)$ & $(-2.75$ to 7.50$)$ \\
1 & +1.53 & +1.35 \\
& $(-1.50$ to +7.50$)$ & $(-2.00 \text { to }+7.50)^{\mathrm{a}}$ \\
2 & +1.06 & +1.29 \\
& $(-7.00$ to +3.50$)$ & $(-9.50 \text { to }+7.50)^{\mathrm{h}}$ \\
$3 / 4$ & -0.32 & -0.42 \\
& $(-3.25$ to +1.50$)$ & $(-5.00$ to +2.75$)$ \\
\hline
\end{tabular}

With increasing ROP severity there is a trend towards myopia, from stage 0 to 2 , reaching significance only between stage 2 and 3 (right eye, $p<0.001$; left eye, $p<0.001$ ). Stage 0 , one infant with +7.50 DS.

"One infant with $-10.00 /+4.00$ (a) due to cataract excluded from analysis.

${ }^{\mathrm{b}}$ One infant with -9.50 , this latter due to cataract. Full ranges in parentheses. 
Table V. Stage of acute ROP and mean astigmatism (in dioptres) for 387 infants refracted between 20 and 45 weeks corrected age

\begin{tabular}{lcc}
\hline Stage of ROP & $\begin{array}{c}\text { Right dioptres } \\
\text { (range) }\end{array}$ & $\begin{array}{c}\text { Left dioptres } \\
\text { (range) }\end{array}$ \\
\hline 0 & +0.81 & +0.80 \\
1 & $(0.00$ to +4.00$)$ & $(0.00$ to +4.50$)$ \\
+0.78 & +0.99 \\
2 & $(0.00$ to +4.25$)$ & $(0.00$ to +4.00$)$ \\
+0.99 & +0.93 \\
$3 / 4$ & $(0.00$ to +2.75$)$ & $(0.00$ to +3.00$)$ \\
& +1.53 & +1.60 \\
\hline
\end{tabular}

With increasing ROP severity there is an increase in magnitude, only reaching significance between stages 2 and 3 (right eye, $p=0.01$; left eye, $p=0.009$ ). Full ranges in parentheses.

increased significantly (left, $p=0.010$; right, $p=0.002$ ). The axis of astigmatism, expressed as a positive cylinder, by ROP stage for right and left eyes respectively is shown in Tables VII and VIII. Anisometropia $\geqslant 1.0 \mathrm{D}$ was present in 23 infants: $3.9 \%(7 / 181)$ of stage $0,3.3 \%(4 / 123)$ of stage $1,7.7 \%(5 / 65)$ of stage 2 , and $41.2 \%(7 / 17)$ of stage 3 infants. These results show a significant relation $(p<0.001)$ between anisometropia and ROP stage, but the numbers at stage 3 were small. As only one eye of one baby was treated with cryotherapy, no comment is made on the effect of this treatment on refraction.

Twenty-six other ocular findings were recorded at 6 months. These were as follows, with numbers of infants in parentheses: nystagmus (4), mild blepharophimosis (4), optic atrophy (3), double elevator palsy (2, in identical twins), ${ }^{26}$ disc coloboma (2), lens subluxation (1), cataract (1), uveitis (1), microphthalmos (1), eyelid haemangioma (1), simple anisocoria (1), limbal dermoid (1), optic nerve hypoplasia (1), ptosis (1), pigmented retina (1) and homonymous hemianopia (1). Some infants had more than one abnormality.

\section{DISCUSSION}

There have been a number of studies reporting the ophthalmic findings in infants and children born prematurely, but as mentioned above, relatively few have compared ophthalmic data from neonatal and subsequent periods. We have recently studied prospectively a cohort of infants of birthweight $\leqslant 1700 \mathrm{~g}(n=572)$ commencing in the

Table VI. Stage of acute ROP and mean spherical equivalent (in dioptres) for 387 infants refracted between 20 and 45 weeks corrected age

\begin{tabular}{lcc}
\hline Stage of ROP & $\begin{array}{c}\text { Right dioptres } \\
\text { (range) }\end{array}$ & $\begin{array}{c}\text { Left dioptres } \\
\text { (range) }\end{array}$ \\
\hline 0 & +1.85 & +1.87 \\
1 & $(-1.50$ to +7.50$)$ & $(-1.88$ to +8.00$)$ \\
+1.91 & +1.84 \\
2 & $(-0.50$ to +7.75$)$ & $(-0.75$ to +7.50$)$ \\
+1.55 & +1.76 \\
$3 / 4$ & $(-6.25$ to +4.00$)$ & $(-8.00$ to +8.00$)$ \\
& +0.45 & +0.38 \\
\hline
\end{tabular}

With increasing ROP severity there is a trend towards myopia, from stage 0 to 2 , reaching significance only between stages 2 and 3 (right eye, $p=0.002$; left eye, $p=0.003$ ). Full ranges in parentheses.
Table VII. Stage of acute ROP and axis of astigmatism for right eye in 387 infants refracted between 20 and 45 weeks corrected age. Numbers of infants for each ROP stage are given, with percentages in parentheses

\begin{tabular}{lccccc}
\hline & \multicolumn{5}{c}{ Stage of ROP } \\
\cline { 2 - 6 } Axis & 0 & 1 & 2 & $3 / 4$ & Total \\
\hline $60^{\circ}-120^{\circ}$ & 88 & 48 & 19 & 1 & 156 \\
& $(60.3 \%)$ & $(54.6 \%)$ & $(42.2 \%)$ & $(8.3 \%)$ & 112 \\
$150^{\circ}-30^{\circ}$ & 51 & 31 & 21 & 9 & 11 \\
Other & $(34.9 \%)$ & $(35.2 \%)$ & $(46.7 \%)$ & $(75.0 \%)$ & 23 \\
& 7 & 9 & 5 & 2 & 23 \\
Total & $(4.8 \%)$ & $(10.2 \%)$ & $(11.1 \%)$ & $(16.7 \%)$ & \\
\hline
\end{tabular}

For infants who never developed ROP the predominant axis is $60^{\circ}-120^{\circ}$, but with increasing ROP severity there was a significant trend away from this axis $(p=0.01)$ and the proportion at other axes increased.

neonatal period in order to study the natural history of acute ROP. ${ }^{20}$ Here we have presented the ophthalmic findings of this cohort at 6 months corrected age and compared them with data obtained during the neonatal period.

The incidence of strabismus $(6.4 \%)$ was lower than that noted in previous studies, ${ }^{7-11.13-19}$ which ranged from $9 \%$ to $25 \%$. The various cohorts are not directly comparable and testing at 6 months almost certainly underestimated the long-term situation. In part this may explain the discrepancy with other studies, all of which studied older infants, or children. We report, for the first time, that strabismus is significantly associated with both the presence and stage of acute ROP, rising from $3.1 \%$ in those without ROP to $29.2 \%$ with stage 3 disease. Kushner ${ }^{10}$ also reported an increased incidence of strabismus in infants with regressed mild ROP compared with preterms who had not developed ROP. Infants with obvious abnormalities of the central nervous system were excluded by Kushner, but there was no mention of neonatal neurological evaluation, and he acknowledged that subtle abnormalities may not have been detected. Schaffer et al. ${ }^{13}$ found no major difference in the incidence of strabismus, amblyopia and refractive errors in infants with regressed mild ( sstage 2) ROP and those who had not developed retinopathy. Strabismus is a well-known associate of neurological abnormalities and several studies have excluded abnormalities of the central nervous system in order to investigate the association between strabismus

Table VIII. Stage of acute ROP and axis of astigmatism for left eye in 387 infants refracted between 20 and 45 weeks corrected age. Numbers of infants for each ROP stage are given, with percentages in parentheses

\begin{tabular}{lccccc}
\hline & \multicolumn{5}{c}{ Stage of ROP } \\
\cline { 2 - 6 } Axis & 0 & 1 & 2 & $3 / 4$ & Total \\
\hline $60^{\circ}-120^{\circ}$ & 103 & 42 & 19 & 3 & 167 \\
$150^{\circ}-30^{\circ}$ & $(66.5 \%)$ & $(55.3 \%)$ & $(40.4 \%)$ & $(23.1 \%)$ & \\
& 31 & 26 & 18 & 5 & 80 \\
Other & $(20.0 \%)$ & $(34.2 \%)$ & $(38.3 \%)$ & $(38.45 \%)$ & \\
& 21 & 8 & 10 & 5 & 44 \\
Total & $(13.5 \%)$ & $(10.5 \%)$ & $(21.3 \%)$ & $(38.45 \%)$ & \\
\hline
\end{tabular}

For infants who never developed ROP the predominant axis is $60^{\circ}-120^{\circ}$. but with increasing ROP severity there was a significant trend away from this axis $(p=0.002)$ and the proportion at other axes increased. 
and ROP. However, these results must be interpreted with caution for the method of exclusion is often relatively crude, as recognised by Kushner. ${ }^{10}$ Gibson et al..$^{17}$ in a prospective study of infants with a birthweight $\leqslant 1500 \mathrm{~g}$ who had regular cranial ultrasound examinations in the neonatal period noted an overall incidence of strabismus of $10 \%(13 / 127)$, but $50 \%$ in those with cystic periventricular leucomalacia $(7 / 14, p<0.001)$ and $70 \%$ in those with posteriorly located cysts. In the present study we also found that abnormal ultrasound cranial events were associated with both the presence and stage of acute ROP $(p=0.001$ and $p<0.001$ respectively), fusional ability $(p<0.001)$ and strabismus $(p<0.001)$. We are not able fully to differentiate ROP and neurological events as causative factors of strabismus, but these results suggest that both may contribute. The mechanism by which regressed ROP may cause strabismus is not immediately obvious, although it is interesting to note that ROP delays development of the macular reflex, ${ }^{27}$ and Mintz-Hittner ${ }^{28}$ reported a retinovascular abnormality of the central retina in survivors of very low birthweight $(\leqslant 750 \mathrm{~g})$. As this was associated with reduced acuity, photoreceptor function is implicated.

The development of visual acuity in preterm neonates is dominated by innate father than environmental influences, and premature exteriorisation appears neither to hasten nor to retard its maturation. ${ }^{29,30}$ Thus on the basis of corrected age, acuity development of preterm and of fullterm infants during the first year of life are in close agreement. ${ }^{29}$ In the present study visual acuity was measured by the acuity card procedure, which unfortunately due to practical constraints was limited in most instances to binocular acuities only. Nevertheless this is the first study to attempt to measure the acuity of a cohort from a prospective study for ROP, and many of the findings are of interest. Of the 431 infants tested, including the 340 infants in which testing was between 20 and 40 weeks corrected age, acuity fell below the normal range in only 8 (as defined by Sebris et al.), ${ }^{31}$ and 2 of these had no grating detection. None of these 8 infants had retinal abnormalities sufficient to account for this finding, but all had severe neurological abnormalities, to which the acuity deficits were attributed. Nevertheless, despite acuities falling within the normal range there is a significant association $(p<0.001)$, at 6 months corrected age, between acuity and the presence and severity of acute ROP, with a trend for lower acuities with increasing severity (Fig. 1). This trend persisted after removal of the 8 infants with abnormally low values and correction for both age at examination and abnormal cranial ultrasound results. It could not be accounted for by cicatricial retinal changes or the degree of prematurity (i.e. the most immature babies developing severe ROP), as no significant association was noted when acuity was plotted against birthweight or gestational age. Abnormal cranial ultrasound per se was not associated with lower acuity levels. Katsumi et al..$^{32}$ also reported normal development in infants with stage 1 and 2 acute retinopathy and thereafter. Birch and Spencer ${ }^{33}$ have reported slightly lower acuities in infants with regressed ROP (stage not given) who had normal posterior poles - a result which persisted after removal of infants with neurological abnormalities. Luna et $a .^{34}$ reported significantly delayed acuity development in the first 2 years of life in regressed stage 3 ROP, but in contrast to Birch and Spencer ${ }^{33}$ these workers concluded that this delay was due to neurological abnormalities as normal development was noted when the former were removed from the analysis. Our study and those of Luna et al..$^{34}$ and Birch and Spencer ${ }^{33}$ are not strictly analogous. It is also of interest that low, but normal acuities have been reported in older ex-preterm groups such as 4-year-old children, ${ }^{35}$ or ex-preterm teenagers, ${ }^{36}$ and McCormick et al. ${ }^{14}$ reported that only $78 \%$ of preterm children (excluding those with cicatricial ROP) achieved $6 / 6$ acuity compared with $92 \%$ of fullterm children. The relative contributions of ROP and/or neurological damage to acuity development are not known, but two comments are pertinent. First, despite ophthalmoscopically complete regression, lower acuity values can result and knowledge of the maximum ROP stage is important when considering the basis of low visual acuity. Second, the precise relationship of neonatal neurological events to the maturation of visual functions is in many cases uncertain, and ascribing visual significance to certain of these insults (as we and other have done in the past) is prejudging a complex issue.

This is the first study systematically to analyse refractive data by ROP stage. During the neonatal period preterm infants are frequently myopic, ${ }^{37-41}$ but there is a trend towards emmetropia with increasing age, ${ }^{14}$ so that by 6 months there is no difference between preterm and fullterm infants. ${ }^{39}$ Our refractive data obtained at 6 months revealed four changes with increasing severity of acute ROP: 1, a significant trend of the sphere towards myopia; 2 , increased magnitude of astigmatism; 3 , alteration of the axis of astigmatism; and 4, increased incidence of anisometropia. In the first three of these, the significant step was between stage 2 and 3 and not at each stage, although there was an insignificant trend from no ROP to stage 2 . That mild, transient ROP does not significantly influence refractive status is supported by Schaffer et al. ${ }^{13}$ who reported only an insignificant trend towards myopia in regressed mild ROP, but not by Kushner et al. ${ }^{10}$ who noted significant changes. The association of myopia with ROP is well known, $2,5,6,9,11,12,14-16,19,37,42-44$ and myopia is frequently associated with cicatricial disease. Nissenkorn et al. ${ }^{12}$ reported a positive correlation with the severity of cicatricial ROP. Our numbers are too small for comment on this point. There are many reports in the literature on astigmatism and anisometropia being associated with ROP, but these aspects have not, as yet, been studied systematically. The mechanism(s) of refractive development in preterm infants with ROP is unknown, but is in all probability multifactorial and influenced by the severity, location and duration of acute ROP. Our results support the long-held tenet that the effect of mild ROP (stages 1 and 2) on ocular growth is minimal, in contrast to the effect of stage 3 ROP. The ROP process occurs at a period 
of rapid ocular development and involves the part of the eye most actively growing, ${ }^{45}$ so it is not surprising that growth of the peripheral retina and the whole anterior portion of the eye may be retarded by acute ROP, and further restricted during cicatrisation. ${ }^{3,6}$ Anomalies of corneal diameter, ${ }^{6}$ corneal curvature, ${ }^{3,46,47}$ lens power ${ }^{5}$ and axial length ${ }^{2,5}$ have been reported which may contribute to the eventual refractive status. We have shown that the axis of astigmatism which is predominantly 'with the rule' without ROP exhibits a significant trend away from this axis with increasing ROP severity. Noted before, ${ }^{48}$ this is the first time the axis of astigmatism has been studied systematically. Although the mechanism producing this alteration of axis direction is not known, it could be influenced by restriction of ocular growth during all ROP phases acting predominantly in the temporal and/or nasal regions. Interocular differences of axis direction could be expected as asymmetry is characteristic of cicatricial ROP.

We have undertaken an intensive study into the natural history of ROP and here we have presented our findings at 6 months corrected age. As at this early age maturation of the eye and the remainder of the visual system is far from complete these data have certain limitations and do not necessarily indicate the long-term situation. Nevertheless they improve understanding of the sequence of events which in turn may contribute to our knowledge of the kinetics and mechanisms of ocular growth and visual development. It is to be hoped that this will lead to the appropriate timing of clinical interventions in this potentially blinding condition.

We thank paediatric and nursing colleagues at the neonatal units in Leicester, Derby and Nottingham for their help and encouragement. Thanks to Dipika Price for undertaking orthoptic assessment on some infants in Leicester. YKN was supported by the Medical Research Council and JR by the Royal National Institute for the Blind.

Key words: Infant, Refraction, Retinopathy of prematurity, Strabismus, Visual acuity.

\section{REFERENCES}

1. Fledelius HC: Prematurity and the eye. Ophthalmic follow-up of children of low and normal birthweight. Acta Ophthalmol 1976, 128 (Suppl): 1-245.

2. Tasman W: Late complications of retrolental fibroplasia. Ophthalmology 1979, 86: 1724-40.

3. Hittner HM, Rhodes LM, McPherson AR: Anterior segment abnormalities in cicatricial retinopathy of prematurity. Ophthalmology 1979, 86: 803-16.

4. Hungerford J, Stewart A, Hope P: Ocular sequelae of preterm birth and their relation to ultrasound evidence of cerebral damage. Br J Ophthalmol 1986, 70: 463-8.

5. Gordon RA, Donzis PB: Myopia associated with retinopathy of prematurity. Ophthalmology 1986, 93: 1593-8.

6. Kelly SP, Fielder AR: Microcornea associated with retinopathy of prematurity. Br J Ophthalmol 1987, 71: 201-3.

7. Burgess P, Johnson A: Ocular defects in infants of extremely low birth weight and low gestational age. $\mathrm{Br} J$ Ophthalmol 1991, 75: 84-7.

8. Gallo JE, Lennerstrand G: A population-based study of ocular abnormalities in premature children aged 5 to 10 years. Am J Ophthamol 1991, 111: 539-47.

9. McGinnity FG, Bryars JH: Controlled study of ocular mor- bidity in school children born preterm. Br J Ophthalmol In press.

10. Kushner BJ: Strabismus and amblyopia associated with regressed retinopathy of prematurity. Arch Ophthalmol 1982, 100: 256-61.

11. Keith CG, Kitchen WH: Ocular morbidity in infants of very low birthweight. Br J Ophthalmol 1983, 67: 302-5.

12. Nissenkorn I, Yassur Y, Mashkowski I, Sherf I, Ben-Sira I: Myopia in premature babies with and without retinopathy of prematurity. Br J Ophthalmol 1983, 67: 170-3.

13. Schaffer DB, Quinn GE, Johnson L: Sequelae of arrested mild retinopathy of prematurity. Arch Ophthalmol 1984, 102: $373-6$.

14. McCormick AQ, Tredger EM, Dunn HG, Grunau RVE: Ophthalmic disorders. In: Dunn HG, editor. Sequelae of low birthweight, the Vancouver study. Clinics in developmental medicine 95-96. Oxford: Mackeith Press, Blackwell Scientific Publications 1986, pp. 127-46.

15. Snir M, Nissenkorn I, Sherf I, Cohen S, Ben-Sira I: Visual acuity, strabismus, and amblyopia in premature babies with and without retinopathy of prematurity. Ann Ophthamol 1988, 20: 256-8.

16. Cats BP, Tan KEWP: Prematures with and without regressed retinopathy of prematurity: comparison of longterm (6-10 years) ophthalmological morbidity. J Pediatr Ophthalmol Strabismus 1989, 26: 271-5.

17. Gibson NA, Fielder AR, Trounce JQ, Levene MI: Ophthalmic findings in infants of very low birthweight. Dev Med Child Neurol 1990, 32: 7-13.

18. Koole FD, Bax PP, Samson JF, van der Lei J: Ocular examination in nine-month-old infants with very low birthweights. Ophthalmic Paediatr Genet 1990, 11: 89-94.

19. Keith CG, Doyle LW, Kitchen WH: Ocular morbidity in extremely low birthweight infants. In: Campos EC, editor. Strabismus and ocular disorders. Proceedings of the Sixth Meeting of the International Strabismological Association. London: Macmillan Press, 1990, pp. 527-35.

20. Fielder AR, Shaw DE, Robinson J, Ng YK: Natural history of retinopathy of prematurity: a prospective study. Eye, 1992, 6: 233-42.

21. Ng YK, Fielder AR, Shaw DE, Levene MI: Epidemiology of retinopathy of prematurity. Lancet 1988 , ii: $1235-8$.

22. Committee for the Classification of Retinopathy of Prematurity: An international classification of retinopathy of prematurity. Arch Ophthalmol 1984, 102: 1130-5.

23. Reese AB, King MJ, Owens WC: A classification of retrolental fibroplasia. Am J Ophthalmol 1953, 36: 1333-5.

24. McDonald MA, Dobson V, Sebris SL, Baitch L, Varner D, Teller DY: The acuity card procedure: a rapid test of infant acuity. Invest Ophthalmol Vis Sci 1985, 26: 1158-62.

25. Lavery JR, Gibson JM, Shaw DE, Rosenthal AR: Refraction and refractive errors in an elderly population. Ophthalmic Physiol Opt 1988, 8: 394-6.

26. Bell JA, Fielder AR, Viney S: Congenital double elevator palsy in identical twins. J Clin Neuro Ophthalmol 1990, 10: 32-4.

27. Isenberg SJ: Macular development in the premature infant. Am J Ophthalmol 1986, 101: 74-80.

28. Mintz-Hittner HM, McGee JK, Kogan A, Miranda G, Kretzer FL: Abnormal foveal avascular zone in very, very low birthweight infants ( $<750$ grams) with or without severe retinopathy of prematurity. Invest Ophthalmol Vis Sci 1990, 31 (Suppl): 117.

29. Birch EE, Spencer R: Monocular grating acuity of healthy preterm infants. Clin Vis Sci 1991, 6: 331-4.

30. Fielder AR, Foreman N, Moseley MJ, Robinson J: Prematurity and visual development. In: Simons $\mathrm{K}$, editor. Handbook of infant vision. Laboratory and clinical research. Oxford: Oxford University Press. In press. 
31. Sebris SL, Dobson V, McDonald MA, Teller DY: Acuity cards for visual assessment of infants and children in clinical settings. Clin Vis Sci 1987, 2: 45-58.

32. Katsumi O, Mehta MC, Matsui Y, Tetsuka H, Hirose T: Development of vision in retinopathy of prematurity. Arch Ophthalmol 1991, 109: 1394-8.

33. Birch EE, Spencer R: Visual outcome in infants with cicatricial retinopathy of prematurity. Invest Ophthalmol Vis Sci 1991, 32: 410-15.

34. Luna B, Dobson V, Biglan AW: Development of grating acuity in infants with regressed stage 3 retinopathy of prematurity. Invest Ophthalmol Vis Sci 1990, 31: 2082-7.

35. Sebris SL, Dobson V, Hartmann EE: Assessment and prediction of visual acuity in 3- to 4-year-old children born prior to term. Hum Neurobiol 1984, 3: 87-92.

36. Fledelius HC: Ophthalmic changes from 10 to 18 years. A longitudinal study of sequels to low birthweight. II. Visual acuity. Acta Ophthalmol 1981, 59: 64-70.

37. Fletcher MC, Brandon S: Myopia of prematurity. Am J Ophthalmol 1955, 40: 474-81.

38. Graham MV, Gray OP: Refraction of premature babies' eyes. Br Med J 1963, i: 1452-4.

39. Shapiro A, Yanko L, Nawratzki I, Merin S: Refractive power of premature children at infancy and early childhood. Am J Ophthalmol 1980, 90: 234-8.

40. Dobson V, Fulton AB, Manning K, Salem D, Petersen RA: Cycloplegic refractions of premature infants. Am J Ophthalmol 1981, 91: 490-5.
41. Linfield PB, Davis JG: A study of the change in mean sphere refractive errors obtained from very low birthweight infants. In: 1st International Congress, British College of Ophthalmic Opticians (Optometrists), London 1984, pp. 197-200.

42. Seiberth V, Knorz MC, Trinkmann R: Refractive errors after cryotherapy in retinopathy of prematurity. Ophthalmologica 1990, 201: 5-8.

43. Ben-Sira I, Nissenkorn I, Weinberger D, Shohat M, Kremer I, Krickler R, Reisner SH: Long-term results of cryotherapy for active stages of retinopathy of prematurity. Ophthalmology 1986, 93: 1423-8.

44. Cryotherapy for Retinopathy of Prematurity Cooperative Group. Multicentre trial of cryotherapy for retinopathy of prematurity. One year outcome - structure and function. Arch Ophthalmol 1990; 108: 1408-16.

45. Fielder AR, Moseley MJ, Ng YK: The immature visual system and premature birth. Br Med Bull 1988, 44: 1093-118.

46. Fledelius HC: Ophthalmic changes from 10 to 18 years. A longitudinal study of sequels to low birthweight. III. Ultrasound oculometry and keratometry of the anterior segment. Acta Ophthalmol 1982, 60: 393-402.

47. Fledelius HC: Inhibited growth and development as permanent features of low birthweight. Acta Paediatr Scand 1982, 71: 645-50.

48. Reynolds JD: Anisometropic amblyopia in severe posterior retinopathy of prematurity. Binoc Vis Quart 1990, 5: 153-8. 